\title{
Malignant Glioma Tumor Lysate-Pulsed Autologous Dendritic Cell Vaccine
}

National Cancer Institute

\section{Source}

National Cancer Institute. Malignant Glioma Tumor Lysate-Pulsed Autologous Dendritic

Cell Vaccine. NCI Thesaurus. Code C74057.

A cell-based cancer vaccine composed of autologous dendritic cells (DCs) pulsed with lysates from malignant glioma cells with potential immunostimulatory and antineoplastic activities. Upon administration, malignant glioma tumor lysate-pulsed autologous dendritic cell vaccine exposes the immune system to undefined malignant glioma tumorassociated antigens (TAAs), which may result in anti-tumoral cytotoxic T lymphocyte (CTL) and antibody responses against glioma cells and glioma cell lysis. 